\title{
Psycho-social correlates of health and health behaviors
}

\author{
Jürgen Barth \\ PD Dr. Jürgen Barth is Senior Researcher at the Department of Social and Preventive Medicine, University of Bern, Switzerland, \\ and Head of the Section of Psychosocial Rehabilitation at the Institute of Psychology, University of Freiburg, Germany
}

This issue of the International Journal of Public Health gives insights into different health related problems and health care models from all over the world. Interesting results from Brazil, Czech Republic, Germany, Hungary, Poland, Slovakia and Switzerland are presented. I am pleased to be given the opportunity to summarize some of these results. All the more, as all papers have in common that they refer to large samples applying complex methodologies, and present a wide range of relevant topics for the understanding of public health issues. They report both on rather well known risk behaviour like smoking or physical activity which are of interest for population studies, and for comprehensive interventions (Azevedo et al. 2006; von Lengerke et al. 2006), but they also address more specific topics like HIV prevention (Balthasar et al. 2006).

Furthermore, gender aspects of health behaviour are explicitly addressed in two papers (Azevedo et al. 2006; Schneider 2006), but also analysed and discussed as a covariate in some of the other papers. All in all, the results clearly support the need for different public health interventions for women and men. Beginning with the latter there is the gender aspect of physical activity: Azevedo et al. conducted a survey on physical activity in Brazil and analyzed gender specific patterns (Azevedo et al. 2006). The paper reports less physical activity in women compared to men, but also thoroughly discusses different activity patterns of men and women in everyday-life. Whereas men took up more structured efforts towards physical activities women probably exercise more during household and occupational activities. Evidence for gender tailored interventions is given by the authors. In the theoretically based paper of Schneider, four hypotheses on the influence of the socio economic status on mortality in Germany were tested (Schneider 2006). Gender aspects play their role insofar as men reported being smokers more often and having higher alcohol consumption than women. These figures on gender-specific smoking and alcohol consump- tion support already reported results in earlier studies of the German population (Lambert \& Burger 2004; Lambert \& Thamm 2004).

The brief report by Baska et al. shows that environmental tobacco smoke (passive smoking) is a serious health concern in adolescence (Baska et al. 2006). Their results show that passive smoking at the home of adolescents is quite common in Hungary, Poland and Slovakia. A more strict law with respect to public smoking should be added to intervention strategies for children. Single intervention strategies often fail if they are not embedded in a comprehensive program (Schulze et al. 2006). The paper by von Lengerke et al. analyzed a large sample of the German KORA study regarding obesity and health related topics like sense of coherence, health related locus of control, and quality of life (von Lengerke et al. 2006). The results indicate that one out of ten people suffer from high obesity. These highly obese people are at risk for developing a metabolic syndrome, and accordingly, are at risk for multimorbidity and severe health complications. The data of von Lengerke et al. does not support the intuitive hypothesis that obesity is associated with health related locus of control beliefs. One might expect lower self responsibility in highly obese patients, which was not supported by the data. Nevertheless, the question remains: Does it make sense to assess health related locus of control beliefs in further studies even in the light of these results? I think yes: The combination of the subscales of health locus of control beliefs might give hints for specific subgroups (e.g. persons with low self responsibility and high chance) and their need for specific motivation strategies (Barth \& Härter 1996).

Balthasar et al. did a comprehensive survey in Switzerland, asking over 1000 male participants about homosexual practices (Balthasar et al. 2006). The study was even more intriguing as it is not only a cross-sectional "snap-shot", but also reveals a longitudinal perspective. The authors were able to 
show differences in sexual behaviour between the early nineties (when HIV was a non-treatable disease with poor prognosis) and nowadays. Today, men with changing partners often regard an HIV infection as a chronic disease which can be treated by medication increasing the life expectancy and quality of life. Unfortunately, regarding HIV as a potentially treatable disease led to more dangerous sexual behavior (e.g. less condom use). As a consequence, HIV prevention strategies should still address the safety of sexual practices in men having sex with men without presenting negative stereotypes. Coming back to Germany, a brief report by Laubach and Fischbeck analyzes the work situation of physicians in a university hospital in Germany (Laubach \& Fischbeck 2006). The authors found a higher satisfaction rate with the own financial situation in older age groups. This result enlivens the recent discussion in Germany about the financial and overall job situation of physicians working in hospitals. Especially the working conditions for younger physicians were claimed as being unsatisfying (for the discussion please see: www.marburger-bund.de). Laubach and Fischbeck also report a remarkable gender difference: Whereas in men the status with respect to "superiors and hierarchy" predicted job satisfaction, women found it more satisfying to work in a good team. This leads to the impression that the promotion scheme for academics in a university setting is predominantly tailored to men with the consequence that women have to seek for another subsystem within the clinic to find their work satisfying. However, these results raise important questions with respect to the current understanding of doing a satisfying job as a medical doctor by relying exclusively on academic promotion; this practice may be only satisfying for men.

In another brief report by Müller et al. the authors present an interesting approach with respect to the underrepresented issue of measuring health related quality of life in hospital settings. They combine this important issue with the very popular measurement instrument SF-36, as they developed a SF-36 hospital version. (Müller et al. 2006). They point out the problem that the wording of the SF 36 probably is inadequate for inpatients, because most of the items refer to situations at home or at work. The authors also pioneer, as they explicitly address response shift as being a risk for poor validity and sensitivity. The knowledge from empirical studies concerning response shift is still scarce, as it is a rather theoretically discussed topic (Güthlin 2004; Sprangers \& Schwartz 1999). The results of Müller et al. imply the need to bear context effects in mind when measuring health related quality of life. Although the SF 36 is established as a gold standard in international research it is still of value to get an idea of what prompts the answers of respondents.

Congratulation goes to all the authors for their methodologically sound and clinically important work on different health related problems and health behaviours. This issue of IJPH shows two important things: The diversity of public health research, which makes public health such a rich field of research and it underlines the necessity to develop creative approaches to support individuals to improve their health. It is worth the effort!

Jürgen Barth

\section{References}

Azevedo MR, Pavin Araújo CL, Fossati Reichert F, Vinholes Siqueira F, Cozzensa da Silva M, Hallal $C P$ (2006). Gender differences in leisure-time physical activity. Int J Public Health 52(1), 8-15.

Balthasar H, Jeannin A, Dubois-Arber F (2006). Surveillance des comportements face au VIH/ sida chez les hommes ayant des rapports sexuels avec des hommes - suisse, 1992-2004. Int J Public Health 52(1), 27-35.

Barth J, Härter M (1996). Gesundheitliche Kontrollüberzeugungen und gesundheitliches Risikoverhalten - eine Analyse von Kontrollüberzeugungsmustern. Psychotherapie, Psychosomatik. Medizinische Psychologie 46: 247-53.

Baska T, Sovinová H, Németh A, et al. (2006). Enviromental tobacco smoke of youngsters in Czech Republic, Hungary, Poland and Slovakia Findings from the Global Youth Tobacco Survey. Int J Public Health 52(1): 62-66.

Güthlin C (2004). Response Shift: alte Probleme der Veränderungsmessung, neu angewendet auf gesundheitsbezogene Lebensqualität. Zeitschrift für Medizinische Psychologie 13(4): 165-74.

Lambert T, Burger M (2004). Rauchgewohnheiten in Deutschland - Ergebnisse des telefonischen Bundes-Gesundheitssurveys 2003. Gesundheitswesen 66: 511-7.

Lambert T, Thamm M (2004). Soziale Ungleichheit des Rauchverhaltens in Deutschland. Bundesgesundheitsblatt 47: 1033-42.

Laubach W, Fischbeck S (2006). Job satisfaction and work situation of physicians: a survey at a german university hospital. Int J Public Health 52(1): 54-59.

Müller H, Franke A, Resch KL (2006). Application of the German SF-36 in hospitals: Overestimations in the four psychosocial scales. Int J Public Health 52(1): 60-61.

Schneider S (2006). Ursachen schichtspezifischer Mortalität in der Bundesrepublik Deutschland: Tabakkonsum dominiert alle anderen Risikofaktoren. Int J Public Health 52(1): 39-53.
Schulze A, Mons U, Edler L, Pötschke-Langer M (2006). Lack of sustainable prevention effect of the »Smoke-Free Class Competition « on German pupils. Preventive Medicine 42(1): 33-9.

Sprangers MA, Schwartz CE (1999). Integrating response shift into health-related quality of life research: a theoretical model. Soc Sci Med 48(11): 1507-15.

von Lengerke T, Janßen C, John J (2006). Sense of coherence, health locus of control and quality of life in obese adults: physical limitations and psychological normalcies. Int J Public Health 52(1): 16-26.

\section{Address for correspondence}

PD Dr. Jürgen Barth

University of Bern

Department of Social and Preventive Medicine

Division of Social and Behavioural Health Research

Niesenweg 6

CH-3012 Bern

e-mail: jbarth@ispm.unibe.ch 